\title{
ENGINEERING TEACHING AND LEARNING FELLOWS AS Catalysts of Change Management in EngineEring EDUCATION
}

\author{
Deena Salem, Brian Frank \\ Faculty of Engineering and Applied Science, Queen's University \\ deena.a.salem@queensu.ca
}

\begin{abstract}
In this paper, the authors present an ethnographical study of Engineering Teaching and Learning Fellows (ETLFs). This paper is part of a longitudinal study that proposes an ecological model of higher education, adapted from Bronfenbrenner's ecological systems theory including, micro, meso, exo, and macro environments. Froyd's change strategies in the academic engineering context are embedded in this social model, together with a different perspective of how ETLFs are situated as catalysts of change management in engineering education. The objective of this study is to provide insight to different stakeholders who are interested in improving the quality of undergraduate students' learning about how the ETLFs can support the changes.
\end{abstract}

Keywords: Teaching and Learning Fellows, Engineering Education, Change Management, Undergraduate, Course Transformation

\section{INTRODUCTION}

Engineering programs across Canada have experienced increasing enrollment of undergraduate students, rising in 2016 to 84,446 engineering students, with a growth rate of approximately $50 \%$ over the last decade. International students enrolled in engineering programs across Canada make up almost $16 \%$ of the total number [1], which contributed approximately $\$ 12.8$ billion to Canada's GDP in 2016 [2] compared to $\$ 39.4$ billion in the USA for the same year [3]. The expansion of engineering programs across the country [4] has heightened the competition between different engineering schools to attract more students with higher cognitive skills. Engineering schools' main concerns are how to stand out from the pack and which changes would give them this advantage.

In 2017, a study was conducted by Seng Kiat Kok and Claire McDonald in the UK's Liverpool Business School [5] in which the authors investigated the correlation between leadership, governance, and management behaviours of high-performing academic departments. Data was collected from 600 participants across 50 different academic departments in five UK universities.
The main finding was that change management is a principal area associated with high performance, with the need for certain key people as the means to facilitate change. In 2017, Deena Salem and Brian Frank of Kingston's Queen University [6] presented the concept of employing ETLFs (Engineering Teaching and Learning Fellows) as key players in the transformation process of engineering education. They discussed how embedding an ETLF who has mastered the subject matter and who has expertise in both the education and engineering fields positively affects different phases of the transformation process of the engineering school's education.

The first author of this paper has been an ETLF in a first-tier research institution for two years. The paper aims to disseminate the lessons she learned through this experience and to provide an understanding of the position of ETLFs in the process of change management. It provides an ethnographical study that portrays how she perceives that ETLFs could catalyze and optimize the change-management process.

\section{PRINCIPLES OF CHANGE MANAGEMENT IN HIGHER EDUCATION}

Three different models of change-management strategies, in different contexts, have been integrated to form a four-step model that is implemented in this study. These models are: Froyd's [7] change strategies in an academic engineering context with focus on the curriculum, Stanley's [8] seven principles for change management in the K-12 education context, and Myatt's [9] three steps of organizational change in the corporate context. The steps of the proposed model are:

(i) Define the landscape of the change needed.

(ii) Identify the breadth and depth of the short- and longterm changes to be implemented.

(iii) Engage highly motivated key players in the process.

(iv) Form a community of practice that can promote and sustain the culture of change. 


\section{ECOLOGICAL MODEL OF HIGHER EDUCATION}

For the purpose of this study, Bronfenbrenner's [1014] ecological systems theory is used. It is concerned with the quality and context of children's environment and how this environment affects their growth and development. This theory was applied as a framework to study professional competence problems [16], to identify the factors that affect trainees' professional growth and might cause professional competence problems.

In this paper, the interpretation of Bronfenbrenner's ecological systems theory is modified to align with the context of change management in higher education, as illustrated in Fig. 1.

The proposed ecological model has five levels: individual, microsystem, mesosystem, exosystem, and macrosystem. It positions individuals (instructors and teaching assistants) at the core of the change process, encompassed within the microsystem that defines the direct interactions between the instructors and their students, peer-instructors, and heads of departments as partners in the teaching and learning process.

Following, is the mesosystem, which include a community of educational professional that has the expertise and capacity to support different perspectives of the instructors' teaching practices. In this system the instructor does not actively participate, and yet the interactions within this system influence the interactions in the microsystem.

The exosystem defines the gate-keeping bodies including the CEAB, professional licensing bodies, USAT results, NSSE results, etc.; the instructors are not directly involved in this system but are affected by it because it has a crucial effect on both the micro and meso systems. The macrosystem provides the overarching cultural beliefs within the institution and the community of the role and the expected quality of education, as anticipated by tax payers, city councilors, donors, alumni, parents, etc.

\section{ENGINEERING TEACHING AND LEARNING FELLOWS AS CHANGE CATALYSTS}

In 2012, Ruth Graham [17] at MIT discussed how to achieve positive and sustainable change and how this change can be initiated, implemented, and maintained. She stated: "There is a growing appreciation that the slow pace of change reflects the difficulties of catalysing and sustaining educational reform within engineering departments and schools. The case for reform is recognised; the challenge is to make it happen. The pressing issue for engineering education is not whether but how to change."

ETLFs might be the answer to the challenge posed by Graham. This study's adopted principles of change management in higher education (section 2) provide a framework that defines the diverse roles of ETLFs, which are discussed below:

(i) Develop a plan to review targeted courses, recruit, train classroom observers to use the available tools, efficiently, collate the observers' data. Design and facilitate the students' focus-group protocols and the interviews with the instructors. ETLFs engineering and education backgrounds qualify them to achieve these tasks.

(ii) Collect data that define the current institutional culture of teaching and learning, and the gaps that need to be bridged. Diverse data is collected (see Fig. 2) that includes instructors' surveys, and interviews about institutional culture relevant to teaching and learning, and their teaching practices; classroom observation data of instructional activities, NSSE institutional results, students' focus-group, and instructors' post-delivery interviews. These data are analyzed using multiple methods and the findings inform the change process. ETLFs have the capacity and the experience to conduct the analysis.

(iii) Analyze the data collected and present the findings to the institutional decision makers, such as the department heads, curriculum committees, to identify the short-term and long-term changes that need to be made. These changes should be decided according to their advantage to the teaching and learning process; their feasibility with clear expectations of the strength, weakness, opportunities, and threats; and the availability of a support system that has the expertise to make these changes happen. ETLFs have the expertise to be part of the process.

(iv) Identify and include key-players. Change is anticipated to be a difficult process, which limits some stakeholders' belief in or interest in being involved. Therefore, it is crucial that once the shortand long-term change plans are set, key players are identified. This may be best accomplished through formal and informal discussions between ETLFs and stakeholders. Through such dialogue, the ETLFs can achieve buy in from those who are ready to adopt the change and function as leaders of the process. 


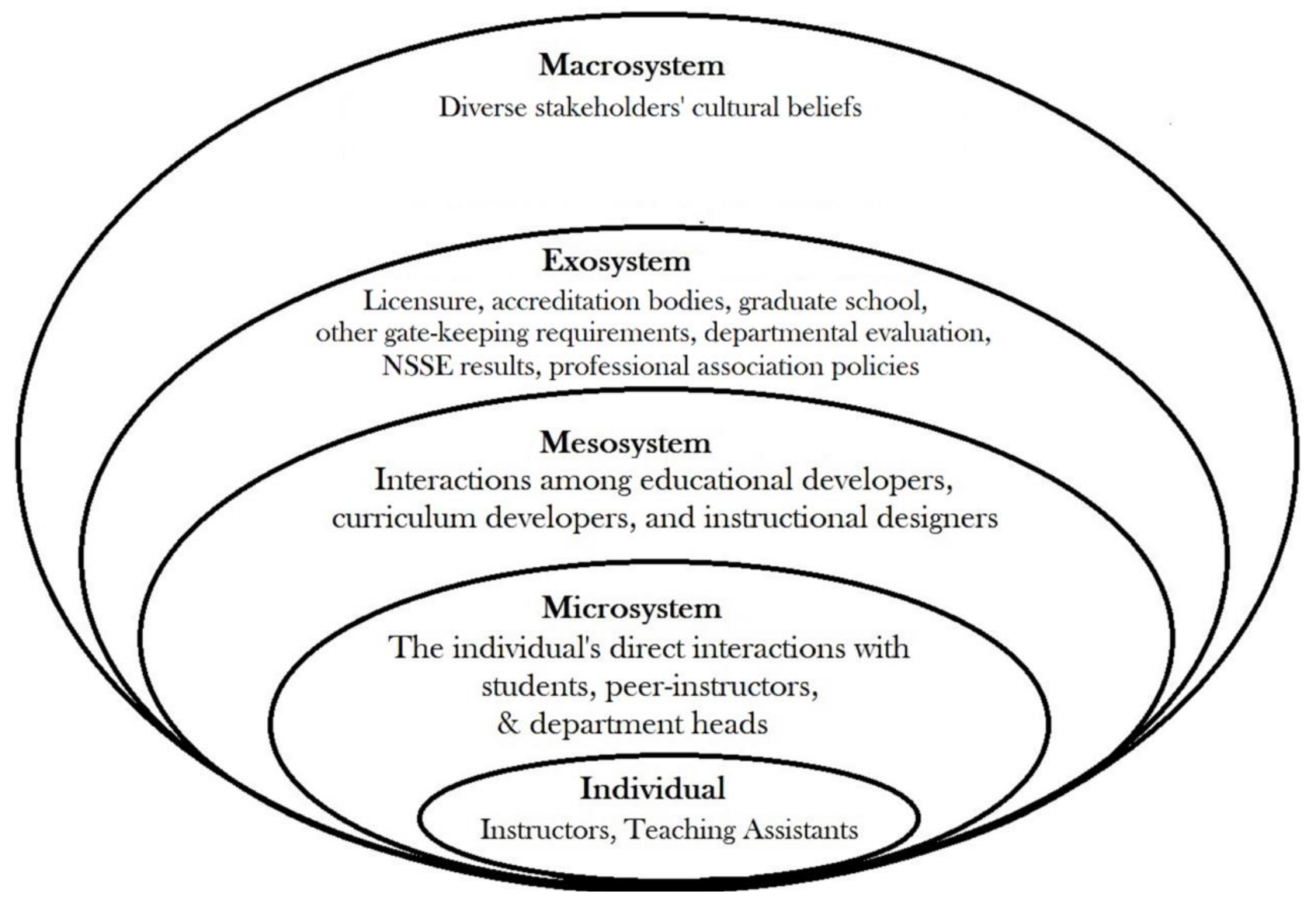

Fig. 1. Ecological model applied to change management in higher education; adapted from [16].

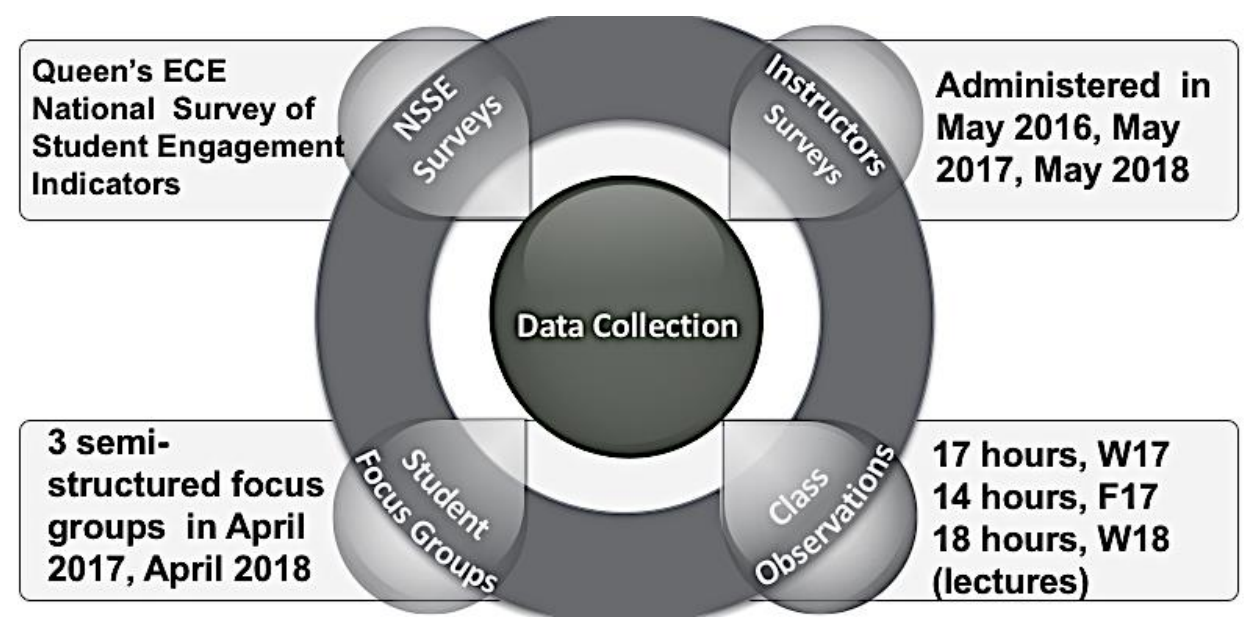

Fig. 2 Data collected every semester to inform the change process

(v) Provide different initiatives that support the formation of a community of practice that can help promote and sustain the culture of change on an institutional level. This might encourage skeptical instructors to get involved.
Referring to the ecological model presented in Fig.1, ETLFs are best suited in the mesosystem as this system includes interactions between ETLFs and administrative personnel, decision makers, and students. All these interactions, although not involving the instructors, 
provide the ETLFs with insights into the system, policies, and culture that affects the ETLFs' performance in a manner that lead to better support of the instructors. Moreover, the ETLFs contribute to the process through their work in the form of providing professional development opportunities to optimize the different backgrounds and levels of training of the graduate teaching assistants involved in the teaching and learning process. Through all these activities, ETLFs support change in the institutional culture of teaching and learning.

\section{Conclusion}

This paper has presented an ecological model of higher education and a four-step model of change-management strategies, as part of an ethnographical study of an ETLF. These two models highlight the broad and essential role of engineering teaching and learning fellows in change management in the higher education context, providing sustainable support to different stakeholders, such as instructors, teaching assistants, heads of departments, and decision makers. This diverse support is made possible by ETLFs' prior disciplinary and educational expertise. It is also achievable by the insight they acquire by being involved in designing and collecting diverse data from different sources, such as students, faculty members, graduates and classroom observations; by analyzing the data collected; and by reporting the findings to relevant stakeholders.

\section{Acknowledgements}

Acknowledge your funding agencies and colleagues involved in the work reported in the paper, but not listed as authors. These guidelines are based on various examples, including the IEEE author guidelines at http://www.ieee.org/publications_standards/publications/a uthors/index.html

\section{References}

[1] https://engineerscanada.ca/reports/canadianengineers-for-tomorrow-2016\#totalundergraduate-student-enrolment

[2] http://www.international.gc.ca/education/reportrapport/impact-2016/index.aspx?lang=eng

[3] https://www.iie.org/Research-and-Insights/OpenDoors/Data/Economic-Impact-of-InternationalStudents

[4] https://www.theglobeandmail.com/news/national lengineering-programs-in-ontario-universitieslook-to-expand/article29307185/
[5] Seng Kiat Kok and Claire McDonald, "Underpinning excellence in higher education - an investigation into the leadership, governance and management behaviours of high-performing academic departments," Studies in Higher Education, vol. 42, no.2, pp. 210-231, 2015.

[6] Deena Salem and Brian Frank, "The role of engineering teaching and learning fellows in the transformation process of ECE courses," in Proc. CEEA Canadian Engineering Education Conf., CEEC17, (Toronto, ON, 4-7 June 2017), 2017.

[7] J. Froyd, D. Penberthy and K. Watson, "Good educational experiments are not necessarily good change processes," in Proc. $30^{\text {th }}$ Annual Frontiers in Education Conference. Building on A Century of Progress in Engineering Education Conf. (IEEE Cat. No.00CH37135) (Kansas City, MO, 18 - 21, October 2000) pp. F1G/1-F1G/6. 2000

[8] Gordon Stanley, "Seven Principles for Change Management," Sustainable Leadership in Education, (September 2006), pp. 1-10, 2006.

[9] https://www.forbes.com/sites/mikemyatt/2012/0 2/07/how-to-lead-change-3-simplesteps/\#429de66e400b

[10] Urie Bronfenbrenner, The ecology of human development. Cambridge: Harvard University Press, 1979.

[11] Urie Bronfenbrenner, "Ecology of the family as a context for human development: Research perspectives," Developmental Psychology, no. 22, pp.723-742, 1986.

[12] Urie, Bronfenbrenner, Recent advances in research on the ecology of human development," R. K. Silvereyes, K. Effort, \& G. Rudner. (Eds.). Development as action in context: Problem behavior and normal youth development. New York: Springer-Verlag, 1986.

[13] Urie Bronfenbrenner, "Ecological systems theory," Annuals of Child Development, no.6, pp.187-249, 1989.

[14] Urie Bronfenbrenner, "Developmental ecology through space and time: A future perspective," in Proc. Examining lives in context: Perspectives on the ecology of human development, Moen, G. H. Elder, \& K. Luscher. (Eds.). (Washington, DC: American Psychological Association), 1995.

[15] Linda Forrest, David Shen Miller, and Nancy Elman, "Psychology trainees with competence problems: From individual to ecological conceptualizations," Training and Education in Professional Psychology, vol.2, no.4, pp. 183-192, 2008.

[16] Ruth Hilary Graham, Achieving excellence in engineering education: the ingredients of successful change, London: Royal Academy of Engineering, 2012. 